Review

\title{
Argonaute 2: A Novel Rising Star in Cancer Research
}

\author{
ZhenLong Ye, HuaJun Jin ${ }^{\bowtie}$, QiJun Qian ${ }^{凶}$ \\ Laboratory of Viral and Gene Therapy, Eastern Hepatobiliary Surgery Hospital, Second Military Medical University, Shanghai 200438, \\ China
}

\begin{abstract}
$\square$ Corresponding authors: Qi-Jun Qian, Tel: + 86-21-81875371; Fax: + 86-21-65580677; E-mail: qianqj@sino-gene.cn; Hua-Jun Jin, Tel: + 86-21-81875372; E-mail: hj-jin@hotmail.com
\end{abstract}

(C) 2015 Ivyspring International Publisher. Reproduction is permitted for personal, noncommercial use, provided that the article is in whole, unmodified, and properly cited. See http://ivyspring.com/terms for terms and conditions.

Received: 2015.01.30; Accepted: 2015.04.15; Published: 2015.07.16

\begin{abstract}
AGO2 (Argonaute 2, EIF2C2) is the only member in AGO family with catalytic activity and of extreme importance during small RNAs guided gene silencing processes. The structural investigations have provided insights into details and functional mechanisms of the four major domains within $\mathrm{AGO}$. As a multifunction player, $\mathrm{AGO} 2$ has been revealed involved in tumorgenesis through miRNAs-dependent or independent ways. And nowadays, AGO2 has also been more importantly found ectopically over-expressed in carcinomas and closely associated with aspects of cancers in means of interacting with well-known tumor factors. Here, we provide a review on structural insights, functional mechanisms, novel roles and relationship with carcinomas of AGO2.
\end{abstract}

Key words: Argonaute-2, carcinomas, microRNAs, angiogenesis

\section{Introduction}

AGO2 (Argonaute-2), also termed as EIF2C2, belongs to the Argonaute family which is highly conserved in species and symbolized by PIWI domain and crescent PAZ domain [1]. Human Argonaute family can be divided into two subfamilies: one is AGO subfamily, including AGO1, AGO2, AGO3, AGO4, and similar with Arabidopsis thaliana AGO1; the other is PIWI subfamily, including HIWI1, HIWI2, HIWI3, HIWI4, and similar with Drosophila PIWI. PIWI subfamily proteins are exclusively expressed in germ-line cells, but AGO subfamily proteins are broadly expressed in most tissues [2,3].

In human AGO family, AGO2 has been revealed as the only member with catalytic activity and essential role within RISC complex, so to regulate small RNAs guided gene silencing processes [1]. Notably, different from other members of AGO family including AGO1, AGO3 and AGO4, AGO2 has also been proved indispensable in murine embryonic development by the finding that knock-out Ago2 gene was lethal $[4,5]$. In 2012, the crystal structure of human AGO2 combined with pre-miRNAs was revealed, and functional details of the four major domains were also clearly clarified, including the $\mathrm{N}$ domain which initiates duplex RNAs unwinding during RISC assembly, the PAZ domain which contains a variant $O B$ fold and binds to 3 ' overhang of small RNAs, the MID domain which recognizes $5^{\prime}$ nucleotides of the guide RNAs through Rossmann-like fold, and the PIWI domain which endows AGO2 catalytic activity due to its putative slicer catalytic site [1].

\section{Structural Information and Functional Molecular Mechanisms of AGO2}

\subsection{Structural Information}

Recent studies on the structure of AGO2 have revealed the four core domains and details of their functions. The four domains array into a bi-lobe format consisting of N-PAZ and MID-PIWI, and connected by Linker 1 (L1) and Linker 2 (L2). The two lobes form a gap which accommodates the guide small RNAs and their complementary fragments in the middle [6]. The details of each core domain will be discussed below and simply showed in figure 1 . 


\begin{tabular}{|c|c|c|c|c|c|}
\hline $\begin{array}{l}\text { Unwind } \\
\text { RNA } \\
\text { duplex }\end{array}$ & & $\begin{array}{c}3 \text { ' } \\
\text { overhang } \\
\text { binding }\end{array}$ & & $\begin{array}{cc}5^{\prime} & \text { m7GpppG } \\
\text { overhang } \\
\text { binding }\end{array} \begin{array}{c}\text { cap } \\
\text { binding }\end{array}$ & $\begin{array}{c}\text { Catalytic } \\
\text { Activity }\end{array}$ \\
\hline $\mathrm{N}$ & L1 & PAZ & L2 & MID & PIWI \\
\hline
\end{tabular}

Fig 1. Linearized depiction of human AGO2. Four major domains and their core functions are showed.

N Domain: During the formation of RISC complex, unwinding of the RNAs, wrapped inside AGO2 is a rate limiting step. In this process, slicer dependent or independent, functional $\mathrm{N}$ domain is indispensable. However, $\mathrm{N}$ domain is not required for RNA loading or slicing [7]. In Thermus thermophilus, $\mathrm{N}$ domain has another important role by stopping the base pairing between guide RNAs and target mRNAs right at the 16th base of the guide RNAs [8]. For eukaryotic AGO2, this function of $\mathrm{N}$ domain has not been showed.

PAZ Domain: PAZ domain exists in both AGO2 and Dicer, and highly conserved in species and characterized by its OB-fold structure which binds to single nucleotide strand through anchoring the 2-nucleotide of $3^{\prime}$ overhang. And this is considered as the main function of PAZ domain in AGO2 [9]. To confirm this, mutant PAZ and its impact on AGO2 were also investigated, and found that AGO2 with mutant PAZ domain could still interact with small RNAs, but was unable to unwind small RNAs or consequently form RISC complex. So PAZ domain/N-PAZ lobe is strictly required for AGO2 to form RISC complex [10, 11].

MID Domain: Among PAZ and PIWI domains, MID domain adopts Rossmann-like fold and provides a binding pocket for $5^{\prime}$ overhang of the guide RNAs [12]. Additionally, MID domain has another assistant site close to this binding site to function synergistically. Both sites have the same two sulfate ions and highly conserved Lys 599 and Lys 638, this renders MID domain the affinity toward m7GpppG cap on target mRNAs [13].

PIWI Domain: PIWI domain exerts three major functions within AGO2, including enduing RNase $\mathrm{H}$ like endonucleolytic activity, containing tryptophan binding area which is critically needed for the enrollment of GW182 and other tryptophan rich factors, regulating the interaction between MID domain and DNA/RNA due to the polarity and hydrophily on the surface of MID-PIWI lobe, for whose stability maintenance, the D603 on PIWI domain is indispensable $[14,15]$.

\subsection{Molecular Mechanisms of AGO2 Functions}

As a multi-role player, AGO2 plays important role in small RNAs guided gene silencing processes, including RNA interference, translation repression and heterochromatinization. The functional mecha- nisms are discussed below.

Degradation of mRNAs: As a core element of RISC complex, AGO2 could directly initiate the degradation of target mRNAs through its catalytic activity in gene silencing processes guided by siRNAs or miRNAs, and this is also a rate limiting step of RNA interference [16, 17]. So, over expression AGO2 by genetic manipulation might be promising in improving the RNA interference drug efficacy and decreasing side effect due to its ability to enhance RNA interference validity [18].

Translation Repression: Researches have already revealed that $\mathrm{AGO} 2$ could repress target gene translation in at least four ways: 1) competing with translation initiating factor eIF4E in binding to $\mathrm{m} 7 \mathrm{G}$ cap of target mRNAs, so to hinder the assembly of ribosome and translation initiation [19]; 2) blocking the formation of 80 s ribosome from 60 s and 40 s ribosome by recruiting eIF6, then to stop translation initiation [20]; 3) inducing the de-adenylation, uncapping and degradation of target mRNAs by recruiting GW182 through its P470 and P505 sites [21]; 4) combining with other AGO proteins, like AGO1 and/or AGO3, to form PUF/AGO/eEF1A complex, which inhibits the extension of peptides during translation [22].

Heterochromatinization: AGO2 is normally located on euchromatin instead of heterochromatin, combining with $\mathrm{CTCF} / \mathrm{CP} 190$, and then inhibits related target gene expression through $\mathrm{CTCF} / \mathrm{CP} 190$ dependent Fab-8 insulation. And this regulatory pattern of AGO2 is RNA interference independent [23]. Another study reported that AGO2 could be occasionally located on euchromatin with AGO1 together, and this facilitated spliceosome recruitment and formation, then promoted the H3K9 methylation of specific exons with the assistance from Dicer and HP1r, so to selectively modulate the transcription elongation efficacy of RNA polymerase and improve gene alternative splicing [24].

Other Mechanisms: In addition to serve as an executor of target mRNAs degradation or gene silencing guided by miRNAs, AGO2 could also act as an RNA slicer in Dicer independent way, and regulator of miRNAs maturation [25, 26]. Researchers have also found that AGO2 could enhance miRNAs stability. By these two ways, AGO2 improves gene silencing guided by miRNAs [27]. The functional mechanisms of AGO2 will be described in figure 2 . 


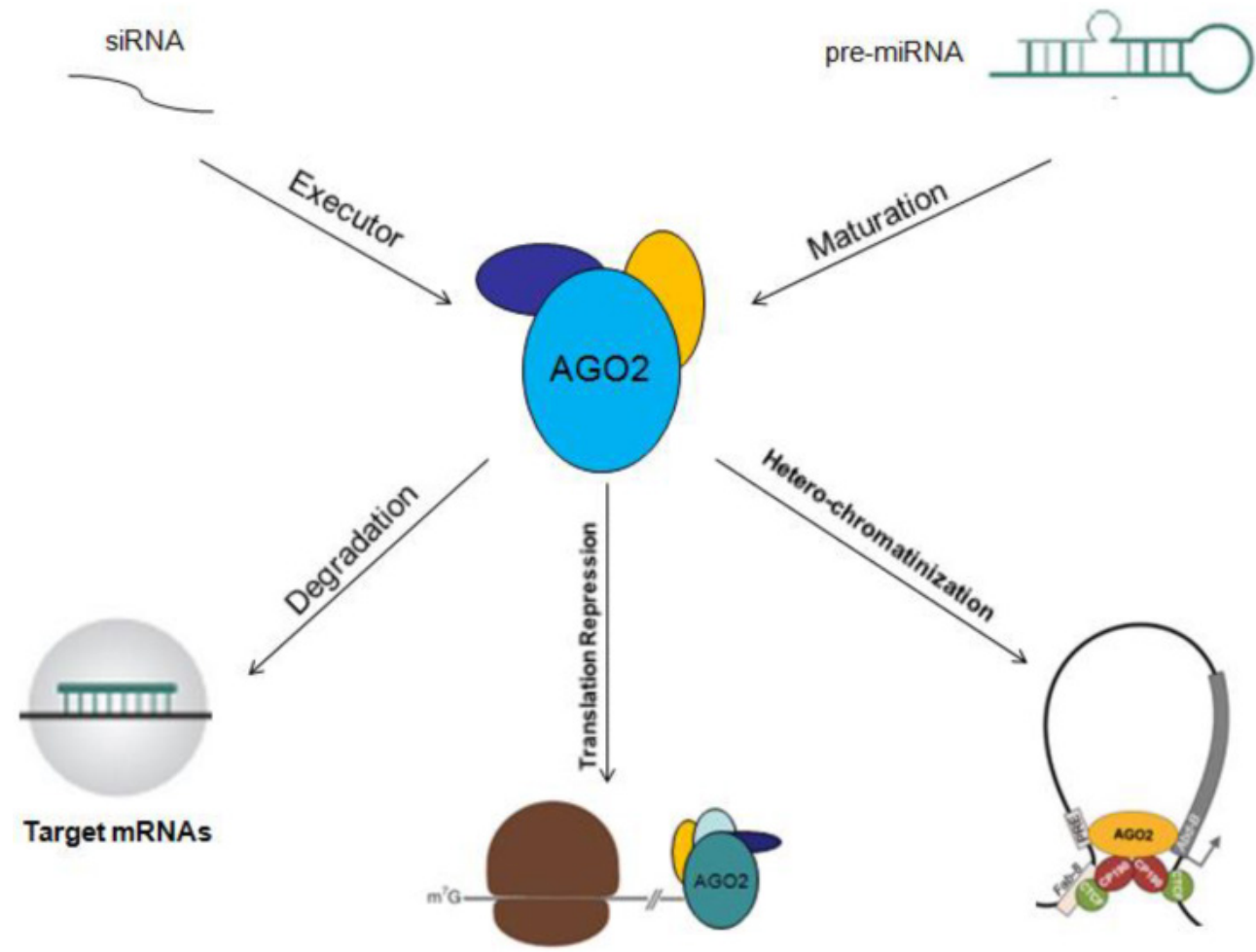

Fig 2. Functional mechanisms of $A G O 2$ are showed. $A G O 2$ could serve as initiator of target mRNAs degradation, stopper of target gene translation, regulator of miRNAs abundance, function, maturation and stability.

\section{AGO2 in Carcinomas}

\subsection{AGO2 is Over-expressed in Cancers}

Data have showed that miRNAs are critical in tumorgenesis. As a key regulator of miRNAs function and maturation, AGO2 has also been found over-expressed in carcinomas, including Colon Cancer [28], Head and Neck Squamous Cell Cancer [29], Urothelial Carcinoma of Bladder [30], Ovarian Carcinoma [31], Gastric Carcinoma [32], and Colorectal Carcinoma [33]. And the over-expression of AGO2 has been proved to be related to aspects of cancers, including tumor cell growth, overall survival of cancer patients [34, 35]. We and others have previously showed that AGO2 was frequently over-expressed in HCC (Hepatocellular Carcinoma) tissues and cell lines, the over-expression of AGO2 facilitated oncogenic miRNAs (like miR-21) to repress targets, but the regulatory capacity of tumor suppressive miRNAs (like let-7) was contrary unaltered [35, 36]. We also creatively found and reported feed-back regulatory loop between AGO2 and miRNAs by revealing that AGO2 could be reciprocally inhibited by miR-99a which was remarkably decreased in HCC tissues. But contradict to the conclusion made by other groups that in our previous study we did not found significant impact of knocking down Ago2 on HCC cell propagation in vitro. Whereas, knocking down Ago2 did severely impaired tumor growth of HCC in vivo. The overview of AGO2 in carcinomas is summarized in Table 1.

Table 1. AGO2 in Carcinomas

\begin{tabular}{lllll}
\hline Ref. & Carcinomas & Total & \multicolumn{2}{l}{ AGO2 Expression } \\
\cline { 4 - 5 } & & Cases & Positive Cases & Negative Cases \\
\hline$[28]$ & Colon Carcinoma & 75 & $74(98.67 \%)$ & $1(1.33 \%)$ \\
{$[30]$} & $\begin{array}{l}\text { Urothelial Carcinoma of } \\
\text { Bladder }\end{array}$ & 106 & $96(90.57)$ & $10(9.43 \%)$ \\
{$[31]$} & Ovarian Carcinoma & 103 & $103(100 \%)$ & $0(0 \%)$ \\
{$[33]$} & Colorectal Carcinoma & 76 & $43(56.6 \%)$ & $33(43.4 \%)$ \\
{$[37]$} & Smooth Muscle Carcino- & 110 & $107(97.3)$ & $3(2.7 \%)$ \\
& ma of Soft Tissues & & & \\
{$[38]$} & Prostate Carcinoma & 107 & $61(57 \%)$ & $46(43 \%)$ \\
{$[38]$} & Esophageal Carcinoma & 58 & $34(58.4 \%)$ & $24(41.6 \%)$ \\
{$[34]$} & Gliomas & 129 & $129(100 \%)$ & $0(0 \%)$ \\
{$[39]$} & Myeloma & 53 & $53(100 \%)$ & $0(0 \%)$ \\
{$[35]$} & Hepatocellular Carcinoma & 152 & $105(69.07 \%)$ & $47(30.93 \%)$ \\
\hline
\end{tabular}

However, others reported that in melanoma, AGO2 expression was strongly reduced in protein level, but not mRNA level [40], and over-expression of AGO2 by genetic manipulation could inhibit cell and tumor growth $[41,42]$. This contradiction could be explained as: the expression level of AGO2 is likely variable between cancer types, due to their different miRNAs expression patterns [43, 44]. Moreover, AGO2 has been revealed associated with aspects of cancer, including angiogenesis, metastasis and other 
processes, and the regulatory mechanisms for these processes are heterogeneous among cancer types and stages $[45,46]$. Therefore, miRNAs expression patterns, cancer types, cancer stages and cancer developmental regulation mechanisms are major determinants of AGO2 expression and function. Hence, more elaborated and systematic experimental design will be helpful to exclude variants before conclude the role of $\mathrm{AGO} 2$ in a certain type of cancer.

\subsection{AGO2 Related Pathways in Carcinomas}

As discussed above, miRNAs/oncogenes/tumor suppressive genes are critical in tumorgenesis. As an essential mediator of miRNAs function and maturation, AGO2 could undoubtedly affect tumorgenesis. But recently, AGO2 was also proved function directly without miRNAs participation in cancers by interacting with famous tumor factors. The diagrammatic overview on the role of AGO2 in cancer is described in fig 3.

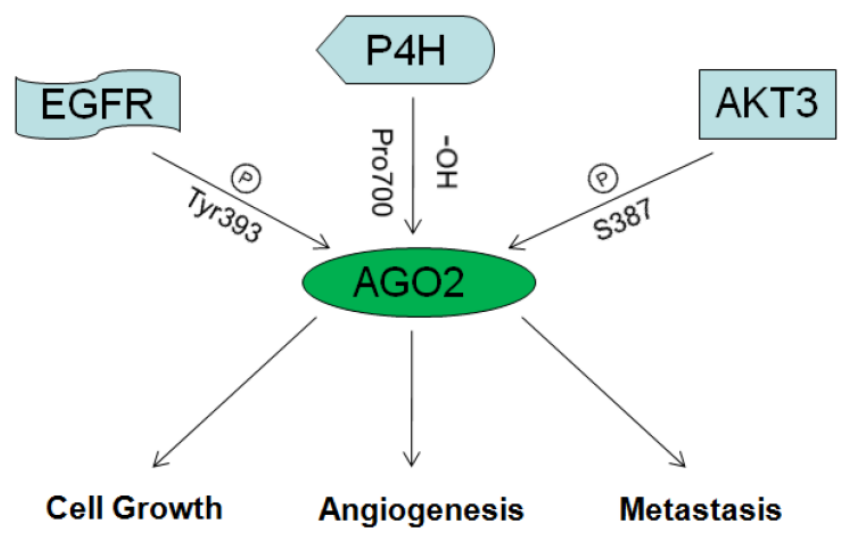

Fig 3. The overview on the role of AGO2 in cancer.

\subsubsection{AGO2 and AKT3}

In 2013, Shane R. Horman and others reported that AKT3 could phosphorylate AGO2 at S387, enhance its binding with GW180 and entry into P-bodies, so to repress expression of target genes. When S387 was not phosphorylated, AGO2 could just function as RNA endonuclease, mediate the degradation of target mRNAs directly. Therefore, AKT3 might be the switch between the two functional patterns of how AGO2 mediates target mRNAs degradation [47].

\subsubsection{AGO2 and EGFR}

In 2013, Jia Shen and others reported that under hypoxia situation, EGFR was frequently over expressed, this led to the improvement of EGFR mediated propagation pathways as well as EGFR desquamation from membranes, desquamated EGFR would be captured by vesicles and transferred into cells. Those transferred EGFR molecules could phos- phorylate AGO2 at Tyr393, and thus attenuate its affinity toward Dicer and impede the maturation of long-loop miRNAs. Interestingly, most long-loop miRNAs were tumor suppressive. So they concluded that, hypoxia situation which occurs frequently in solid tumors, hindered the maturation of tumor suppressive miRNAs through AGO2/EGFR, and consequently promoted the survival and metastasis of tumor cells. They also confirmed this by clinical investigation on the association between AGO2 expression and breast cancer patients' overall survival. Results showed consistence $[48,49]$.

\subsubsection{AGO2 and FAK}

In 2013, Nan Cheng and others showed that AGO2 was over expressed in HCC samples and cells. By chromatin immunoprecipitation they revealed that AGO2 could directly bind to the promoter of FAK, which is a critical molecule associated with tumor metastasis, and trigger its transcription. This led to the improvement of HCC metastasis. In addition, they revealed that the increased copy number of Ago2 on chromosome 8q24 might be the mechanism for AGO2 over-expression [36].

\subsubsection{AGO2 and $\mathrm{P} 4 \mathrm{H}$}

$\mathrm{P} 4 \mathrm{H}$ (Prolyl-4-hydroxylase), which is inhibited under hypoxia situation, was reported as a master of hypoxia response by controlling the stability of HIF [50]. In 2008, Hank H. Qi and others reported the physical interaction between $\mathrm{AGO} 2$ and $\mathrm{P} 4 \mathrm{H}$ subunits $\mathrm{a}-(\mathrm{P} 4 \mathrm{H}-\mathrm{a}(\mathrm{I}))$ and $\beta-(\mathrm{P} 4 \mathrm{H}-\beta)$. By mass spectrometric analysis, they identified that the endogenous AGO2 could be hydroxylated at proline 700 and enhanced by $\mathrm{P} 4 \mathrm{H}$ subunits. Mutation at proline 700 or dysfunction of $\mathrm{P} 4 \mathrm{H}$ subunits resulted in decreased stability of AGO2 [51].

Moreover, AGO2 was also found to regulate FGF2 expression and miRNAs stability. By binding to miRNAs, AGO2 could prolong their half-time, especially for extracellular miRNAs [52]. In 2013, Benoit Laffont and others revealed the mechanism of how AGO2 prolonged miRNAs half-time, that is, the complex of miRNAs/AGO2 could be effectively wrapped by platelet derived micro-particles and transferred into vascular endothelial cells, then affected related signaling pathway inside [53].

\subsection{AGO2 and Cancer Angiogenesis}

Many researches on the mechanism of angiogenesis have revealed that angiogenesis is a complicated process, and intricately regulated by factors including VEGF, PDGF, FGF, TGF, MMP, Angiopoietin, Angiostatin, Endostatin and so on [54]. As essential regulator of gene expression, miRNAs function and executor-DICER has been indicated playing 
important role in tumor angiogenesis [55]. How is AGO2 in angiogenesis?

In 2008, Tomohiro Asai and others proved that AGO2 could directly regulate the angiogenesis of vascular endothelial cells. They also showed that knock-down of Ago2 in HUVECs (human umbilical vein endothelial cells), which are strictly required in vascularization, induced apoptosis and disabled vessel formation [56]. In our previous study, we found that knock-down of $A g o 2$ by siRNAs significantly impaired HCC growth in vivo instead of in vitro. We also astonishingly noticed that the severely attenuated HCC angiogenesis might be a cause for this [35]. By examining the expression of angiogenesis related factors, we found the correlation between AGO2 and VEGF in HCC cell lines. This was confirmed by the reduction of VEGF in vitro and in vivo when we knock-down Ago2. Through further investigations over the underlying mechanisms, we revealed that PTEN was a mediator of the interaction between AGO2 and VEGF (In Press). So AGO2 is probably a potential target for treatment of carcinomas, and it is of great interests to further investigate the relationship and the underlying mechanisms of AGO2 with angiogenesis in other carcinomas.

In addition to be associated with aspects of tumorgenesis, AGO2 has also been proved to be related to stem cell pluripotency maintenance [57], cell differentiation [58], pancreatic $\beta$ cell expansion [42], skeletal muscle homeostasis modulation [59], microvesicles function [60] and hypoxic adaptation [61]. All these newly found roles of AGO2 are enlightening and freshening our understanding of AGO2 in carcinogenesis, but further studies are needed.

\section{Conclusion}

Being an important miRNAs machinery, AGO2 has been found involving in tumorgenesis in a miRNAs-dependent manner. Recently, the alternative role of AGO2 has also been concerned to directly regulate tumorgenesis through interacting with other tumor-associated factors. Although the identified functions of AGO2 across different types of cancer are contradicted, emerging data have undoubtedly showed that AGO2 implicated in the regulation of many biological processes of cancer, including proliferation, metastasis, angiogenesis and et al. Furthermore, the versatile roles of $\mathrm{AGO} 2$ found in normal cells, especial regulation of cell differentiation fate, have broadened potential function of AGO2 in tumorgenesis. In summary, these related works mentioned above have made AGO2 served as a hot target in cancer research.

\section{Acknowledgments}

This work was supported by National Science Funds for general project (No. 81001013) and Creative Research Groups (No. 81221061), Chinese Key Project for Infectious Diseases (No. 2012ZX0002-014-005, 2013ZX10002-010-007), Military Youth Project ( No. 13QNP101 )and State Project For Essential Drug Research and Development (2013ZX09102-060).

\section{Competing Interests}

The authors have declared that no competing interest exists.

\section{References}

1. Hock J, Meister G: The Argonaute protein family. Genome biology 2008, 9(2):210.

2. Meister G: Argonaute proteins: functional insights and emerging roles. Nature reviews Genetics 2013, 14(7):447-459.

3. Schirle NT, MacRae IJ: The crystal structure of human Argonaute2. Science 2012, 336(6084):1037-1040.

4. Morita S, Horii T, Kimura M, Goto Y, Ochiya T, Hatada I: One Argonaute family member, Eif2c2 (Ago2), is essential for development and appears not to be involved in DNA methylation. Genomics 2007, 89(6):687-696.

5. Shekar PC, Naim A, Sarathi DP, Kumar S: Argonaute-2-null embryonic stem cells are retarded in self-renewal and differentiation. Journal of biosciences 2011, 36(4):649-657.

6. Kuhn CD, Joshua-Tor L: Eukaryotic Argonautes come into focus. Trends in biochemical sciences 2013, 38(5):263-271.

7. Kwak PB, Tomari Y: The $\mathrm{N}$ domain of Argonaute drives duplex unwinding during RISC assembly. Nature structural \& molecular biology 2012, 19(2):145-151.

8. Wang Y, Juranek S, Li H, Sheng G, Wardle GS, Tuschl T, Patel DJ: Nucleation, propagation and cleavage of target RNAs in Ago silencing complexes. Nature 2009, 461(7265):754-761.

9. $\mathrm{Ma} J \mathrm{~B}$, Ye K, Patel DJ: Structural basis for overhang-specific small interfering RNA recognition by the PAZ domain. Nature 2004, 429(6989):318-322.

10. Song JJ, Liu J, Tolia NH, Schneiderman J, Smith SK, Martienssen RA, Hannon GJ, Joshua-Tor L: The crystal structure of the Argonaute2 PAZ domain reveals an RNA binding motif in RNAi effector complexes. Nature structural biology 2003, 10(12):1026-1032.

11. Gu S, Jin L, Huang Y, Zhang F, Kay MA: Slicing-independent RISC activation requires the argonaute PAZ domain. Current biology : CB 2012, 22(16):1536-1542.

12. Boland A, Huntzinger E, Schmidt S, Izaurralde E, Weichenrieder O: Crystal structure of the MID-PIWI lobe of a eukaryotic Argonaute protein. Proceedings of the National Academy of Sciences of the United States of America 2011, 108(26):10466-10471.

13. Boland A, Tritschler F, Heimstadt S, Izaurralde E, Weichenrieder O: Crystal structure and ligand binding of the MID domain of a eukaryotic Argonaute protein. EMBO reports 2010, 11(7):522-527.

14. Parker JS, Roe SM, Barford D: Structural insights into mRNA recognition from a PIWI domain-siRNA guide complex. Nature 2005, 434(7033):663-666.

15. Girard A, Sachidanandam R, Hannon GJ, Carmell MA: A germline-specific class of small RNAs binds mammalian Piwi proteins. Nature 2006, 442(7099):199-202.

16. Meister G, Landthaler $M$, Patkaniowska A, Dorsett $Y$, Teng G, Tuschl T: Human Argonaute2 mediates RNA cleavage targeted by miRNAs and siRNAs. Molecular cell 2004, 15(2):185-197.

17. Choe J, Cho H, Lee HC, Kim YK: microRNA/Argonaute 2 regulates nonsense-mediated messenger RNA decay. EMBO reports 2010, 11(5):380-386.

18. Borner K, Niopek D, Cotugno G, Kaldenbach M, Pankert T, Willemsen J, Zhang X, Schurmann N, Mockenhaupt S, Serva A et al: Robust RNAi enhancement via human Argonaute-2 overexpression from plasmids, viral vectors and cell lines. Nucleic acids research 2013, 41(21):e199.

19. Kiriakidou M, Tan GS, Lamprinaki S, De Planell-Saguer M, Nelson PT, Mourelatos Z: An mRNA m7G cap binding-like motif within human Ago2 represses translation. Cell 2007, 129(6):1141-1151.

20. Chendrimada TP, Finn KJ, Ji X, Baillat D, Gregory RI, Liebhaber SA, Pasquinelli AE, Shiekhattar R: MicroRNA silencing through RISC recruitment of eIF6. Nature 2007, 447(7146):823-828.

21. Chen $\mathrm{CY}$, Zheng $\mathrm{D}$, Xia $\mathrm{Z}$, Shyu AB: Ago-TNRC6 triggers microRNA-mediated decay by promoting two deadenylation steps. Nature structural \& molecular biology 2009, 16(11):1160-1166.

22. Friend K, Campbell ZT, Cooke A, Kroll-Conner P, Wickens MP, Kimble J: A conserved PUF-Ago-eEF1A complex attenuates translation elongation. Nature structural \& molecular biology 2012, 19(2):176-183. 
23. Moshkovich N, Nisha P, Boyle PI, Thompson BA, Dale RK, Lei EP: RNAi-independent role for Argonaute2 in CTCF/CP190 chromatin insulator function. Genes $\mathcal{E}$ development 2011, 25(16):1686-1701.

24. Ameyar-Zazoua M, Rachez C, Souidi M, Robin P, Fritsch L, Young R, Morozova N, Fenouil R, Descostes N, Andrau JC et al: Argonaute proteins couple chromatin silencing to alternative splicing. Nature structural \& molecular biology 2012, 19(10):998-1004.

25. Cheloufi S, Dos Santos CO, Chong MM, Hannon GJ: A dicer-independent miRNA biogenesis pathway that requires Ago catalysis. Nature 2010, 465(7298):584-589.

26. Cifuentes D, Xue H, Taylor DW, Patnode H, Mishima Y, Cheloufi S, Ma E, Mane S, Hannon GJ, Lawson ND et al: A novel miRNA processing pathway independent of Dicer requires Argonaute2 catalytic activity. Science 2010, 328(5986):1694-1698

27. Winter J, Diederichs S: Argonaute proteins regulate microRNA stability: Increased microRNA abundance by Argonaute proteins is due to microRNA stabilization. RNA biology 2011, 8(6):1149-1157.

28. Li L, Yu C, Gao H, Li Y: Argonaute proteins: potential biomarkers for human colon cancer. BMC cancer 2010, 10:38.

29. Chang SS, Smith I, Glazer C, Hennessey P, Califano JA: EIF2C is overexpressed and amplified in head and neck squamous cell carcinoma. ORL: journal for oto-rhino-laryngology and its related specialties 2010, 72(6):337-343.

30. Yang FQ, Huang JH, Liu M, Yang FP, Li W, Wang GC, Che JP, Zheng JH: Argonaute 2 is up-regulated in tissues of urothelial carcinoma of bladder. International journal of clinical and experimental pathology 2014, 7(1):340-347.

31. Vaksman O, Hetland TE, Trope CG, Reich R, Davidson B: Argonaute, Dicer, and Drosha are up-regulated along tumor progression in serous ovarian carcinoma. Human pathology 2012, 43(11):2062-2069.

32. Zhang J, Fan XS, Wang CX, Liu B, Li Q, Zhou XJ: Up-regulation of Ago2 expression in gastric carcinoma. Med Oncol 2013, 30(3):628.

33. Papachristou DI, Korpetinou A, Giannopoulou E, Antonacopoulou AG, Papadaki H, Grivas P, Scopa CD, Kalofonos HP: Expression of the ribonucleases Drosha, Dicer, and Ago2 in colorectal carcinomas. Virchows Archiv : an international journal of pathology 2011, 459(4):431-440.

34. Feng B, Hu P, Lu SJ, Chen JB, Ge RL: Increased argonaute 2 expression in gliomas and its association with tumor progression and poor prognosis. Asian Pacific journal of cancer prevention : APJCP 2014, 15(9):4079-4083.

35. Zhang J, Jin H, Liu H, Lv S, Wang B, Wang R, Ding M, Yang Y, Li L, Fu S et al: MiRNA-99a directly regulates $\mathrm{AGO} 2$ through translational repression in hepatocellular carcinoma. Oncogenesis 2014, 3:e97.

36. Cheng N, Li Y, Han ZG: Argonaute2 promotes tumor metastasis by way of up-regulating focal adhesion kinase expression in hepatocellular carcinoma. Hepatology 2013, 57(5):1906-1918.

37. Papachristou DJ, Sklirou E, Corradi D, Grassani C, Kontogeorgakos V, Rao UN: Immunohistochemical analysis of the endoribonucleases Drosha, Dicer and Ago2 in smooth muscle tumours of soft tissues. Histopathology 2012, 60(6B):E28-36.

38. Yoo NJ, Hur SY, Kim MS, Lee JY, Lee SH: Immunohistochemical analysis of RNA-induced silencing complex-related proteins AGO2 and TNRC6A in prostate and esophageal cancers. APMIS : acta pathologica, microbiologica, et immunologica Scandinavica 2010, 118(4):271-276.

39. Wu S, Yu W, Qu X, Wang R, Xu J, Zhang Q, Li J, Chen L: Argonaute 2 promotes myeloma angiogenesis via microRNA dysregulation. Journal of hematology $\mathcal{E}$ oncology 2014, 7(1):40.

40. Voller D, Reinders J, Meister G, Bosserhoff AK: Strong reduction of AGO2 expression in melanoma and cellular consequences. British journal of cancer 2013, 109(12):3116-3124.

41. Zhang X, Graves P, Zeng Y: Overexpression of human Argonaute2 inhibits cell and tumor growth. Biochimica et biophysica acta 2013, 1830(3):2553-2561.

42. Tattikota SG, Rathjen T, McAnulty SJ, Wessels HH, Akerman I, van de Bunt M, Hausser J, Esguerra JL, Musahl A, Pandey AK et al: Argonaute2 mediates compensatory expansion of the pancreatic beta cell. Cell metabolism 2014 19(1):122-134

43. Hayes J, Peruzzi PP, Lawler S: MicroRNAs in cancer: biomarkers, functions and therapy. Trends in molecular medicine 2014, 20(8):460-469.

44. Li Z, Rana TM: Therapeutic targeting of microRNAs: current status and future challenges. Nature reviews Drug discovery 2014, 13(8):622-638

45. Meacham CE, Morrison SJ: Tumour heterogeneity and cancer cell plasticity. Nature 2013, 501(7467):328-337.

46. Junttila MR, de Sauvage FJ: Influence of tumour micro-environment heterogeneity on therapeutic response. Nature 2013, 501(7467):346-354.

47. Horman SR, Janas MM, Litterst C, Wang B, MacRae IJ, Sever MJ, Morrissey DV, Graves P, Luo B, Umesalma S et al: Akt-mediated phosphorylation of argonaute 2 downregulates cleavage and upregulates translational repression of MicroRNA targets. Molecular cell 2013, 50(3):356-367.

48. Shen J, Xia W, Khotskaya YB, Huo L, Nakanishi K, Lim SO, Du Y, Wang Y, Chang WC, Chen $\mathrm{CH}$ et al: EGFR modulates microRNA maturation in response to hypoxia through phosphorylation of AGO2. Nature 2013, 497(7449):383-387.

49. Hauptmann J, Meister G: Argonaute regulation: two roads to the same destination. Developmental cell 2013, 25(6):553-554.

50. Myllyharju J: Prolyl 4-hydroxylases, master regulators of the hypoxia response. Acta Physiol (Oxf) 2013, 208(2):148-165.
51. Qi HH, Ongusaha PP, Myllyharju J, Cheng D, Pakkanen O, Shi $\mathrm{Y}$, Lee SW, Peng J: Prolyl 4-hydroxylation regulates Argonaute 2 stability. Nature 2008, 455(7211):421-424

52. MacFarlane LA, Gu Y, Casson AG, Murphy PR: Regulation of fibroblast growth factor-2 by an endogenous antisense RNA and by argonaute-2. Mol Endocrinol 2010, 24(4):800-812.

53. Laffont B, Corduan A, Ple $\mathrm{H}$, Duchez AC, Cloutier N, Boilard E, Provost P. Activated platelets can deliver mRNA regulatory Ago2*microRNA complexes to endothelial cells via microparticles. Blood 2013, 122(2):253-261.

54. Folkman J: Angiogenesis: an organizing principle for drug discovery? Nature reviews Drug discovery 2007, 6(4):273-286.

55. Chen S, Xue Y, Wu X, Le C, Bhutkar A, Bell EL, Zhang F, Langer R, Sharp PA: Global microRNA depletion suppresses tumor angiogenesis. Genes $\mathcal{E}$ development 2014, 28(10):1054-1067.

56. Asai T, Suzuki Y, Matsushita S, Yonezawa S, Yokota J, Katanasaka Y, Ishida T, Dewa T, Kiwada H, Nango M et al: Disappearance of the angiogenic potential of endothelial cells caused by Argonaute2 knockdown. Biochemical and biophysical research communications 2008, 368(2):243-248.

57. Kim BS, Im YB, Jung SJ, Park CH, Kang SK: Argonaute2 regulation for K+ channel-mediated human adipose tissue-derived stromal cells self-renewal and survival in nucleus. Stem cells and development 2012, 21(10):1736-1748.

58. Iosue I, Quaranta R, Masciarelli S, Fontemaggi G, Batassa EM, Bertolami C, Ottone T, Divona M, Salvatori B, Padula F et al: Argonaute 2 sustains the gene expression program driving human monocytic differentiation of acute myeloid leukemia cells. Cell death $\mathcal{E}$ disease 2013, 4:e926.

59. Neppl RL, Kataoka M, Wang DZ: Crystallin-alphaB regulates skeletal muscle homeostasis via modulation of argonaute2 activity. The Journal of biological chemistry 2014, 289(24):17240-17248.

60. Lv Z, Wei Y, Wang D, Zhang CY, Zen K, Li L: Argonaute 2 in cell-secreted microvesicles guides the function of secreted miRNAs in recipient cells. PloS one 2014, 9(7):e103599.

61. Hale A, Lee C, Annis S, Min PK, Pande R, Creager MA, Julian CG, Moore LG, Mitsialis SA, Hwang SJ et al: An Argonaute 2 switch regulates circulating miR-210 to coordinate hypoxic adaptation across cells. Biochimica et biophysica acta 2014, 1843(11):2528-2542 